\title{
Changes in Mental Health Following the 2016 Presidential Election
}

\author{
Brandon W. Yan, $B A^{7}$ (D), Renee Y. Hsia, MD, MSc ${ }^{1,2}$, Victoria Yeung ${ }^{3}$, and Frank A. Sloan, \\ $P h D^{4}$
}

\begin{abstract}
'Philip R. Lee Institute for Health Policy Studies and School of Medicine, University of California, San Francisco, 513 Parnassus Ave, Suite S-245, San Francisco, CA, United States; ${ }^{2}$ Department of Emergency Medicine, University of California, San Francisco, San Francisco, CA, USA; ${ }^{3}$ University of California, Berkeley, Berkeley, CA, USA; ' Department of Economics, Sanford School of Public Policy, and Margolis Center for Health Policy, Duke University, Durham, NC, USA
\end{abstract}

BACKGROUND: The 2016 presidential election and the controversial policy agenda of its victor have raised concerns about how the election may have impacted mental health.

OBJECTIVE: Assess how mental health changed from before to after the November 2016 election and how trends differed in states that voted for Donald Trump versus Hillary Clinton.

DESIGN: Pre- versus post-election study using monthly cross-sectional survey data.

PARTICIPANTS: A total of 499,201 adults surveyed in the Behavioral Risk Factor Surveillance System from May 2016 to May 2017.

EXPOSURE: Residence in a state that voted for Trump versus state that voted for Clinton and the candidate's margin of victory in the state.

MAIN MEASURES: Self-reported days of poor mental health in the last 30 days and depression rate.

KEY RESULTS: Compared to October 2016, the mean days of poor mental health in the last 30 days per adult rose from 3.35 to 3.85 in December 2016 in Clinton states (0.50 days difference, $p=0.005$ ) but remained statistically unchanged in Trump states, moving from 3.94 to 3.78 days $(-0.17$ difference, $p=0.308)$. The rises in poor mental health days in Clinton states were driven by older adults, women, and white individuals. The depression rate in Clinton states began rising in January 2017. A 10-percentage point higher margin of victory for Clinton in a state predicted 0.41 more days of poor mental health per adult in December 2016 on average $(p=0.001)$.

CONCLUSIONS: In states that voted for Clinton, there were 54.6 million more days of poor mental health among adults in December 2016, the month following the election, compared to October 2016. Clinicians should consider that elections could cause at least transitory increases in poor mental health and tailor patient care accordingly, especially with the 2020 election upon us.

J Gen Intern Med 36(1):170-7

DOI: $10.1007 /$ s11606-020-06328-6

(C) Society of General Internal Medicine 2020

Supplementary Information The online version contains supplementary material available at https://doi.org/10.1007/s11606-020-06328-6.

Received July 29, 2020

Accepted October 16, 2020

Published online October 31, 2020

\section{INTRODUCTION}

President Donald Trump's 2016 election victory and controversial campaign agenda raised concerns about the election's impact on health. ${ }^{1}$ A pre-2016 election survey found that $52 \%$ of Americans considered the election to be a "significant source of stress," while $49 \%$ reported the election outcome to be a significant source of stress in January $2017 .^{2}$ The few published studies assessing the impact of the election on mental health used online search data and small surveys and found evidence of increased stress and anxiety following the election. ${ }^{3-5}$ However, whether this reported stress translates into population-level changes in perceived mental health and diagnosed mental health conditions is largely unknown.

With the 2020 election upon us, understanding the last presidential election's impact on mental health could help health care providers anticipate and better address electionrelated health effects this November and beyond. In this study, we used a large national health survey to analyze changes in mental health and depression in states that voted for Secretary Hillary Clinton versus states that voted for Trump. We further investigated whether changes in mental health were associated with a candidate's margin of victory in a state, which we used as a proxy for voter choice.

\section{METHODS}

\section{Study Design and Data}

We used the 2016 and 2017 editions of the Behavioral Risk Factor Surveillance System (BRFSS), a joint state and federal annual household survey of more than 400,000 adults, to study changes in mental health indicators in Clinton- versus Trumpvoting states in the 6 months following November 2016 compared to 6 months prior. The BRFSS telephone survey is conducted throughout the year using random-digit telephone dialing. Our study design is a monthly cross-sectional study of respondents living in the 50 states and the District of Columbia who responded to the poor mental health survey question from May 2016 to May 2017. For population sizes used in the 
calculation of total days of mental health change in the population, we used the U.S. Census Bureau's 2016 state characteristics population estimates for US adults ages 18 and older.

\section{Study Variables}

There were 2 key explanatory variables. The first was a binary variable set to 1 if the survey respondent lived in a state in which Trump received a plurality of votes in November 2016 and 0 if he did not. We refer to these states as Trump or Clinton states for brevity. The states that voted for Trump were Alabama, Alaska, Arizona, Arkansas, Florida, Georgia, Idaho, Indiana, Iowa, Kansas, Kentucky, Louisiana, Michigan, Mississippi, Missouri, Montana, Nebraska, North Carolina, North Dakota, Ohio, Oklahoma, Pennsylvania, South Carolina, South Dakota, Tennessee, Texas, Utah, West Virginia, Wisconsin, and Wyoming. The states that voted for Clinton were California, Colorado, Connecticut, Delaware, District of Columbia, Hawaii, Illinois, Maine, Maryland, Massachusetts, Minnesota, Nevada, New Hampshire, New Jersey, New Mexico, New York, Oregon, Rhode Island, Vermont, Virginia, and Washington. The second key explanatory variable was a Donald Trump's margin of victory over Hillary Clinton in a particular state (i.e., Trump's proportion of votes minus Clinton's proportion of votes).

We had 3 outcomes of interest. The primary outcome was days of "poor mental health" in the last 30 days (range 0 30 days), which was surveyed as "Now thinking about your mental health, which includes stress, depression, and problems with emotions, for how many days during the past 30 days was your mental health not good?" Responses of do not know, not sure, or refused comprised $1.6 \%$ of responses and were excluded from analysis. The secondary outcome was the rate of 14 or more poor mental health days in the last 30 days (range yes/no), which is important for its relation to one of the Diagnostic and Statistical Manual of Mental Disorders, 5th Edition's criteria for major depressive disorder (MDD) that requires at least 2 weeks of symptoms. Fourteen days of such symptoms alone is insufficient for the diagnosis of MDD but could point towards its possibility. The third outcome was the depression rate, which was surveyed as "Has a doctor, nurse, or other health professional ever told you that you had any of the following? Tell me "Yes", "No", or you are "Not sure": (Ever told) you that you have a depressive disorder, including depression, major depression, dysthymia, or minor depression?" Responses of not sure, do not know, or refused comprised less than $0.5 \%$ of responses and were excluded from analysis of this outcome.

Other explanatory variables used as regression covariates were respondent age $(18-24,25-34,35-44,45-54,55-64$, $65+$ ), sex (male, female), race and ethnicity (non-Hispanic white, non-Hispanic black, Hispanic, and other or unknown race), annual household income $(<\$ 15,000$; $\$ 15,000-\$ 24,999 ; \$ 25,000$ to $\$ 34,999 ; \$ 35,000$ to $\$ 49,999$; $>\$ 50,000$ ), educational attainment (high school graduate or less, attended college or technical school, graduated from college or technical school), state of residence (50 US states and the District of Columbia), and pre-election trends (binary variables for each of the 6 months preceding November 2016).

\section{Statistical Analysis}

Stratifying by Trump states and Clinton states, we analyzed values for the outcome variables in each month for the 6 months following the election compared to values in October 2016. We used ordinary least squares linear regression to fit our model and applied BRFSS survey weights to obtain nationally representative estimates while adjusting for respondent's age group, sex, race/ethnicity, income, educational attainment, state, and 6 months of pre-November trends.

Equation 1 describes our study design:

$$
\text { MentalHealth }_{i j k l m s}=\beta_{0}+\sum_{\substack{y=-6 \\ y \neq-1}}^{6} \beta_{y}\left(t-t_{0}=y\right)+\beta_{i j k l m}+\Omega_{s}+\varepsilon_{i j k l m s}
$$

where $i$ denotes age group; $j$, race/ethnicity; $k$, sex; $l$, income; $m$, education; and $s$, state. The regression modeled mental health outcomes by month $(t)$ relative to the election event $\left(y=0, t_{0}\right.$, November 2016). As the coefficient of interest, $\beta_{y}$ describes the difference in the dependent variable between each month and the month immediately preceding the event (October 2016, $y=-1$ ), the omitted reference group. The $\beta_{y}$ differences between the pre-election months and October $2016(y=-6$ to -1$)$ control for trends in the pre-period. $\beta_{i j k l m}$ is a vector for age, race/ethnicity, sex, income, and education groups. $\Omega$ captures state fixed effects. The regression analysis was survey weighted and used robust standard errors. The analysis was performed for Clinton states and then repeated for Trump states.

We would expect the coefficients for event times $y=-5$, $4,-3$, and -2 to not be statistically different from the reference month $(y=-1)$ if the mental health measure was relatively stable in the months prior to the election. If they are statistically different from $y=-1$, then there is evidence of an existing pre-event trend. In the months following the election (event times $y \geq 0$ ), a statistically significant result would indicate a detectable change in the dependent variable from October 2016 that is independent the previously noted covariates, including any pre-event trend.

In addition, subgroup analyses were performed for age group, sex, and race to provide data on which groups were particularly affected. Survey weights and the same linear model specification were used for each subgroup of respondents.

To analyze the association between a candidate's margin of victory in a state and the change in poor mental health between October 2016 and December 2016, we collapsed the personlevel BRFSS data into a state-level file. We chose these 2 months, the month immediately preceding and the month 
immediately following the election, to mitigate the influence of other events. Because there is variable lag time for when changes in depression might follow from the election, we performed this analysis on the poor mental health variable. The state-level file contained the mean weighted changes in poor mental health from October 2016 to December 2016, as well as the weighted characteristics of the survey respondents $(\mathrm{ijklm})$ in October 2016 and December 2016 by proportion in each state (e.g., weighted proportion of female respondents in October/December 2016 in a particular state). We then used linear regression to estimate the relationship between margin of victory and change in poor mental health, both with and without other covariates (i.e., the survey respondents' characteristics described above).

\section{RESULTS}

A total of 499,201 respondents from May 2016 to May 2017 were included for analysis. Compared to October 2016, the mean number of poor mental health days per adult in the last 30 days increased from 3.35 to 3.85 in December 2016 in Clinton states ( 0.50 days difference, standard error (SE) 0.18 , $p=0.005$ ) but remained statistically unchanged in Trump states, falling from 3.94 to 3.78 days ( -0.17 days difference, SE $0.16, p=0.308$ ). Results from adjusted analysis were very similar (Fig. 1). The additional 0.50 days per adult translated into 54.6 million more days of poor mental health in December 2016 alone for the 109.2 million adults living in Clinton states. Notably, December 2016 was the only month during the 12-month study period when the point estimate of mean poor mental health days was lower in Trump states than in Clinton states. The increase in average poor mental health days in Clinton states and absence of change in Trump states largely persisted in the 6 months post-election even after adjustment for the study covariates (Fig. 1).

Trends in the rate of 14 or more poor mental health days closely followed that of the continuous poor mental health days measure. The proportion of respondents reporting at least 14 days of poor mental health in the last 30 days rose 2percentage points (SE 0.7, $p=0.003$ ) in December 2016 compared to October 2016 and remained steady thereafter in Clinton states, while no such rise was observed in Trump states (Fig. 1).

In subgroup analysis, the rise in poor mental health days in Clinton states in December 2016 reflected increases in such days by adults aged 65 and older, women, and white individuals (Table 1). On average, white adults in Clinton states had 0.74 additional days of poor mental health in the last 30 days in December 2016 than in October 2016 (SE 0.19, $p<0.001$ ). Of the 3 groups with increases, white individuals had the most sustained increase in the 6 months following the election. Notably, no changes in poor mental health days were detected among younger age groups, men, or racial and ethnic minority groups in December 2016 in either Clinton or Trump states. In Trump states, men reported fewer days of poor mental health in December and January than October, although only in January was the difference statistically significant $(0.50$ fewer days, SE 0.24, $p=0.036$ ) (Table 1).

Subgroup findings for the 14-day poor mental health version of this variable were similar with two main exceptions. Older adults in Clinton states did not have a significant increase in 14 or more poor mental health days in December 2016 (2.1-percentage point increase, SE 1.1, $p=0.072$ ) as they did in the continuous measure (Supplemental Table 1), but it should be noted that older adults had the lowest baseline number of poor mental health days of any age group (Table 1). In addition, the fall in mean poor mental health days for men in Trump states in January 2017 did not extend to the 14 or more days measure.

In contrast, depression rates compared to October 2016 first rose statistically in Clinton states in January 2017 (2.1percentage point increase, SE 0.8, $p=0.008$ ), 1 month following the rise in days of reported poor mental health (Fig. 2). This overall rise was driven by more reports of depression in younger adults (ages 18-34) and older adults (Table 2). Depression rates also began rising compared to October 2016 in Trump states in February 2017 (1.8-percentage point increase, $\mathrm{SE} 0.8, p=0.028$ ). In both groups of states, the rise in depression rates continued into the second quarter of 2017 (Fig. 2).

Trump's margin of victory in a state was predictive of the degree of mental health change from October 2016 to December 2016. In adjusted regression analysis, a 10-percentage point higher margin of victory for Trump predicted 0.41 fewer days of poor mental health (SE 0.11, $p=0.001$ ) (Fig. 3). The converse is also true that a 10 -percentage point higher margin of victory for Clinton predicted 0.41 more days of poor mental health.

\section{DISCUSSION}

Following the 2016 election, poor mental health days increased in states that voted for Clinton but remained relatively stable in Trump states. In addition, the margin of Clinton's victory in a state predicted the extent of mental health worsening. Together, the findings suggest that the outcome of the 2016 election had a negative impact on mental health for voters of the losing candidate overall. Although other factors are likely contributory, the sustained mental health worsening in Clinton states in the 6 months following the election suggests that the potential effects of Trump's victory were not transitory, a hypothesis supported by a closely lagging rise in self-reported diagnoses of depression.

In subgroup analysis, it was older adults, women, and white individuals who bore the brunt of mental health worsening in Clinton states. The overall finding in Clinton states is not surprising, as a survey from the American Psychological Association (APA) following the election indicated that more Democrats faced stress from the election outcome than Republicans. ${ }^{2}$ However, that survey found higher rates of election-related stress in racial and ethnic minority groups than 
a)

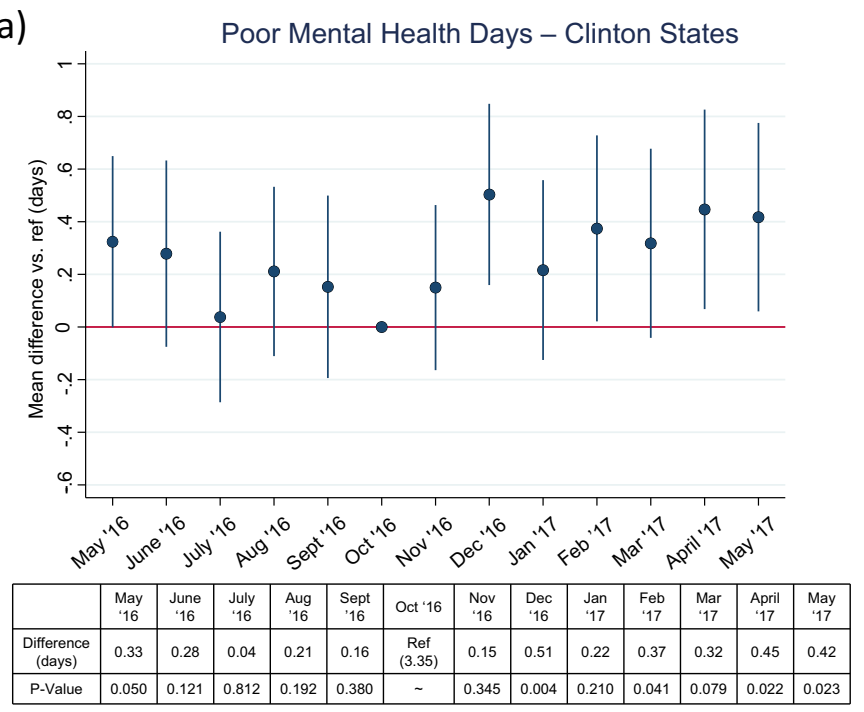

b)

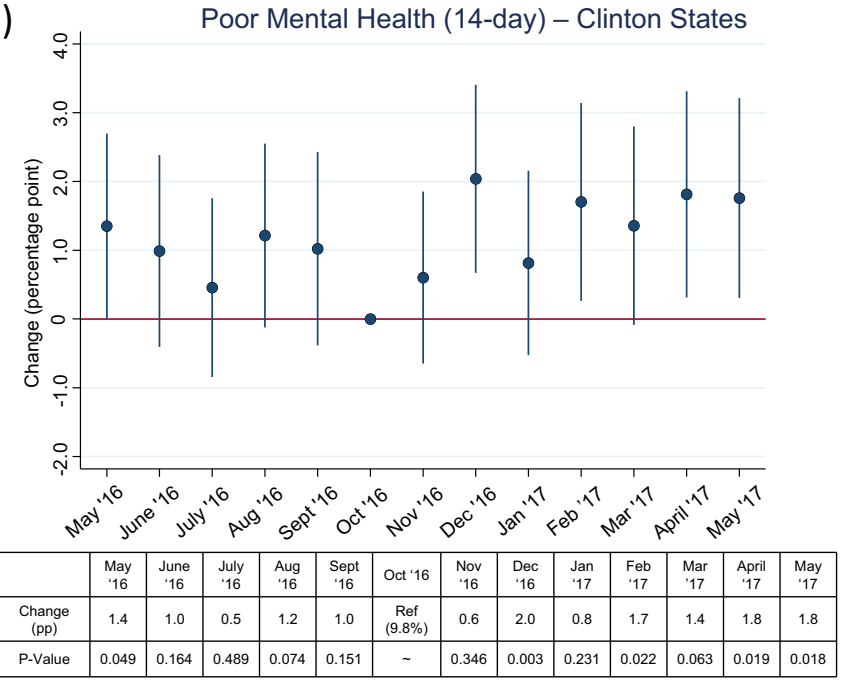

Poor Mental Health Days - Trump States

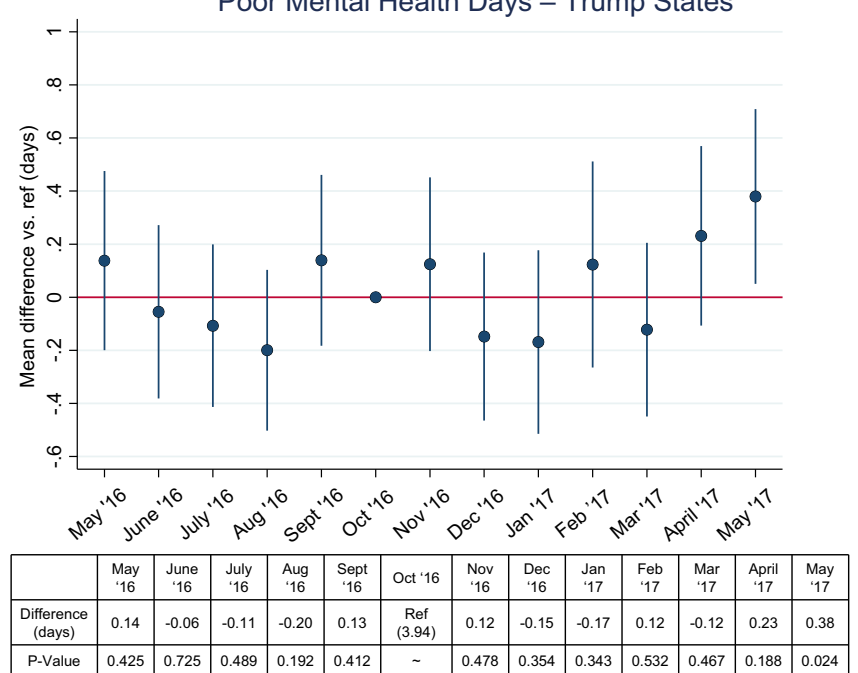

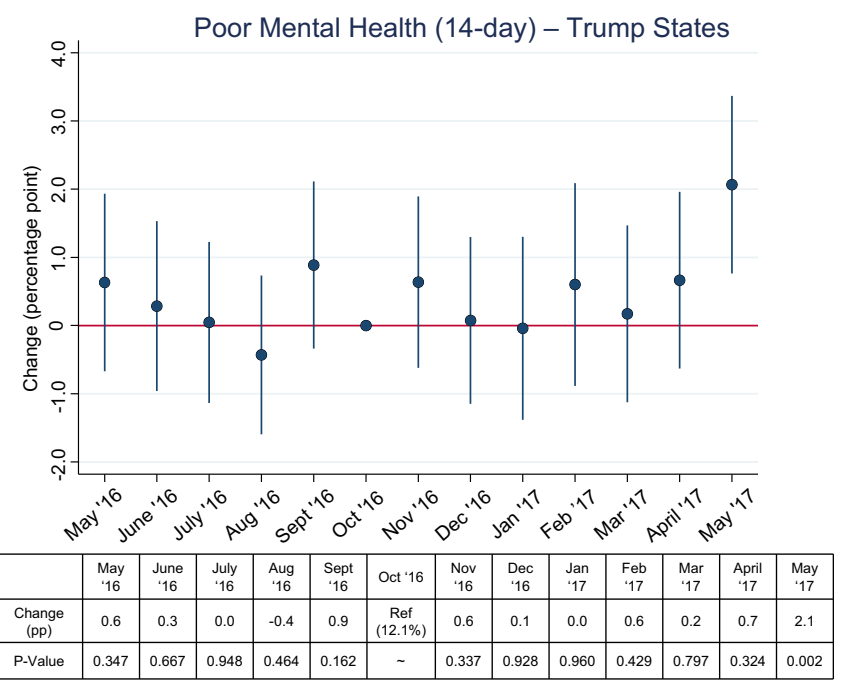

Figure 1 Adjusted changes in measures of mental health in each month compared to October 2016 stratified by states with voting pluralities for Clinton and Trump. (a) Days of poor mental health in the last 30 days (b) Rate of 14 or more days of poor mental health

in white individuals, which contrasts with our study. Some key differences are that the APA survey assessed stress whereas the BRFSS assessed days of poor mental health, and the APA surveyed fewer people $(n=1019)$. Both surveys were available in English and Spanish. A possible explanation is that elevated stress may not necessarily translate to a day of perceived poor mental health. Further research is needed to better understand the impact of the election on mental health in minority populations.

The question of whether the mental health worsening was of clinical significance is also important. It is notable that not only did poor mental health days increase in Clinton states following the election but the proportion of those with 14 or more days also increased, suggesting that a proportion of individuals detectable at the population level may newly meet diagnostic criteria for major depressive disorder. Indeed, the rate of self-reported diagnoses of depression rose in January 2017, 1 month after the first detectable rise in poor mental days. Interestingly, older adults in Clinton states experienced a rise in mean poor mental health days and depression but not rate of 14 or more poor mental health days. We offer a few hypotheses. First, older adults have the lowest baseline number of poor mental health days (mean 2.04 days in Clinton states) compared to other age groups, thus making increases less likely to cross the 14-day threshold. Second, older adults have higher rates of physician visits, which might facilitate the reporting of depressive symptoms to providers who then communicate a diagnosis. ${ }^{6}$ Third, the survey question allows for a provider-made diagnosis of "depression, major depression, dysthymia, or minor depression," so the rise in depression rate among older adults could reflect rises in dysthymia or minor depression instead of major depression, which requires at least 2 weeks of symptoms.

In states that voted for Trump, there was no statistically significant drop in poor mental health following the election, although there was a brief non-significant reduction in 
Table 1 Changes in Poor Mental Health Between Each Month and October 2016 Stratified by Age, Sex, Race/Ethnicity, and State Group

\begin{tabular}{|c|c|c|c|c|c|c|c|c|c|}
\hline \multirow[b]{2}{*}{ Demographic } & \multirow[b]{2}{*}{$\begin{array}{l}\text { State } \\
\text { group }\end{array}$} & \multirow{2}{*}{$\begin{array}{l}\text { Unadjusted } \\
\text { mean days of } \\
\text { poor mental } \\
\text { health, October } \\
2016 \text { (reference) }\end{array}$} & \multicolumn{7}{|c|}{ Adjusted change in days versus October 2016 (SE) } \\
\hline & & & $\begin{array}{l}\text { November } \\
2016\end{array}$ & $\begin{array}{l}\text { December } \\
2016\end{array}$ & $\begin{array}{l}\text { January } \\
2017\end{array}$ & $\begin{array}{l}\text { February } \\
2017\end{array}$ & March 2017 & $\begin{array}{l}\text { April } \\
2017\end{array}$ & May 2017 \\
\hline \multicolumn{10}{|l|}{ Age group } \\
\hline \multirow[t]{2}{*}{ Age $18-34$} & Clinton & 4.24 & $0.37(0.39)$ & $0.63(0.41)$ & $\begin{array}{l}0.14 \\
(0.41)\end{array}$ & $0.22(0.40)$ & $0.06(0.42)$ & $\begin{array}{l}0.77 \\
(0.46)\end{array}$ & $0.74(0.45)$ \\
\hline & Trump & 4.90 & $\begin{array}{l}-0.19 \\
(0.39)\end{array}$ & $\begin{array}{l}-0.08 \\
(0.38)\end{array}$ & $\begin{array}{l}-0.15 \\
(0.41)\end{array}$ & $0.07(0.40)$ & $-0.50(0.37)$ & $\begin{array}{l}0.30 \\
(0.39)\end{array}$ & $0.16(0.35)$ \\
\hline \multirow[t]{2}{*}{ Age $35-54$} & Clinton & 3.58 & $\begin{array}{l}-0.18 \\
(0.27)\end{array}$ & $0.38(0.28)$ & $\begin{array}{l}-0.16 \\
(0.27)\end{array}$ & $0.36(0.30)$ & $0.32(0.32)$ & $\begin{array}{l}0.17 \\
(0.32)\end{array}$ & $\begin{array}{l}-0.04 \\
(0.28)\end{array}$ \\
\hline & Trump & 4.27 & $0.10(0.29)$ & $\begin{array}{l}-0.39 \\
(0.29)\end{array}$ & $\begin{array}{l}-0.15 \\
(0.31)\end{array}$ & $\begin{array}{l}-0.20 \\
(0.32)\end{array}$ & $0.10(0.30)$ & $\begin{array}{l}0.24 \\
(0.31)\end{array}$ & $0.48(0.32)$ \\
\hline \multirow[t]{2}{*}{ Age 55-64 } & Clinton & 3.31 & $0.25(0.34)$ & $0.45(0.44)$ & $\begin{array}{l}0.60 \\
(0.39)\end{array}$ & $0.47(0.40)$ & $0.55(0.37)$ & $\begin{array}{l}1.02 \\
(0.47)^{*}\end{array}$ & $0.33(0.38)$ \\
\hline & Trump & 3.87 & $0.63(0.35)$ & $\begin{array}{l}-0.15 \\
(0.30)\end{array}$ & $\begin{array}{l}-0.53 \\
(0.31)\end{array}$ & $0.44(0.55)$ & $-0.22(0.35)$ & $\begin{array}{l}0.06 \\
(0.33)\end{array}$ & $0.62(0.38)$ \\
\hline \multirow[t]{2}{*}{ Age $65+$} & Clinton & 2.04 & $0.23(0.22)$ & $\begin{array}{l}0.53 \\
(0.25) *\end{array}$ & $\begin{array}{l}0.58 \\
(0.29)^{*}\end{array}$ & $0.45(0.33)$ & $0.40(0.28)$ & $\begin{array}{l}-0.07 \\
(0.23)\end{array}$ & $\begin{array}{l}0.58 \\
(0.28)^{*}\end{array}$ \\
\hline & Trump & 2.35 & $0.18(0.26)$ & $0.05(0.24)$ & $\begin{array}{l}0.05 \\
(0.28)\end{array}$ & $0.29(0.32)$ & $0.01(0.26)$ & $\begin{array}{l}0.24 \\
(0.27)\end{array}$ & $0.33(0.26)$ \\
\hline \multicolumn{10}{|l|}{ Sex } \\
\hline \multirow[t]{2}{*}{ Male } & Clinton & 2.82 & $0.11(0.21)$ & $0.34(0.23)$ & $\begin{array}{l}0.14 \\
(0.23)\end{array}$ & $0.12(0.21)$ & $0.34(0.24)$ & $\begin{array}{l}0.58 \\
(0.25)^{*}\end{array}$ & $\begin{array}{l}0.60 \\
(0.24)^{*}\end{array}$ \\
\hline & Trump & 3.41 & $0.00(0.23)$ & $\begin{array}{l}-0.24 \\
(0.23)\end{array}$ & $\begin{array}{l}-0.50 \\
(0.24)^{*}\end{array}$ & $0.16(0.27)$ & $\begin{array}{l}-0.30 \\
(0.24)\end{array}$ & $\begin{array}{l}0.04 \\
(0.24)\end{array}$ & $0.28(0.23)$ \\
\hline \multirow[t]{2}{*}{ Female } & Clinton & 3.85 & $0.18(0.24)$ & $\begin{array}{l}0.66 \\
(0.26) *\end{array}$ & $\begin{array}{l}0.29 \\
(0.26)\end{array}$ & $\begin{array}{l}0.61 \\
(0.29) *\end{array}$ & $0.31(0.28)$ & $\begin{array}{l}0.33 \\
(0.29)\end{array}$ & $0.24(0.27)$ \\
\hline & Trump & 4.43 & $0.25(0.24)$ & $\begin{array}{l}-0.07 \\
(0.23)\end{array}$ & $\begin{array}{l}0.14 \\
(0.26)\end{array}$ & $0.11(0.29)$ & $0.06(0.24)$ & $\begin{array}{l}0.41 \\
(0.25)\end{array}$ & $0.47(0.24)$ \\
\hline \multicolumn{10}{|l|}{ Race/ethnicity } \\
\hline \multirow[t]{2}{*}{ White } & Clinton & 3.29 & $0.28(0.17)$ & $\begin{array}{l}0.74 \\
(0.19) * * *\end{array}$ & $\begin{array}{l}0.16 \\
(0.19)\end{array}$ & $\begin{array}{l}0.53 \\
(0.20)^{* *}\end{array}$ & $\begin{array}{l}0.56 \\
(0.20)^{* * *}\end{array}$ & $\begin{array}{l}0.60 \\
(0.21)^{* * *}\end{array}$ & $\begin{array}{l}0.81 \\
(0.20) * * *\end{array}$ \\
\hline & Trump & 3.76 & $0.23(0.17)$ & $0.02(0.17)$ & $\begin{array}{l}-0.05 \\
(0.18)\end{array}$ & $0.12(0.18)$ & $0.09(0.18)$ & $\begin{array}{l}0.24 \\
(0.17)\end{array}$ & $\begin{array}{l}0.60 \\
(0.18)^{* * * *}\end{array}$ \\
\hline \multirow[t]{2}{*}{ Black } & Clinton & 4.13 & $\begin{array}{l}-0.12 \\
(0.58)\end{array}$ & $\begin{array}{l}-0.40 \\
(0.56)\end{array}$ & $\begin{array}{l}0.61 \\
(0.71)\end{array}$ & $\begin{array}{l}-0.07 \\
(0.60)\end{array}$ & $-0.36(0.59)$ & $\begin{array}{l}-0.40 \\
(0.64)\end{array}$ & $\begin{array}{l}-0.76 \\
(0.60)\end{array}$ \\
\hline & Trump & 4.12 & $0.24(0.49)$ & $0.06(0.51)$ & $\begin{array}{l}-0.16 \\
(0.50)\end{array}$ & $\begin{array}{l}-0.06 \\
(0.55)\end{array}$ & $-0.32(0.49)$ & $\begin{array}{l}0.89 \\
(0.55)\end{array}$ & $0.18(0.50)$ \\
\hline \multirow[t]{2}{*}{ Hispanic } & Clinton & 3.37 & $0.13(0.50)$ & $0.35(0.50)$ & $\begin{array}{l}0.40 \\
(0.51)\end{array}$ & $\begin{array}{l}-0.39 \\
(0.51)\end{array}$ & $0.06(0.57)$ & $\begin{array}{l}0.47 \\
(0.55)\end{array}$ & $\begin{array}{l}-0.30 \\
(0.50)\end{array}$ \\
\hline & Trump & 3.86 & $0.24(0.77)$ & $\begin{array}{l}-1.11 \\
(0.68)\end{array}$ & $\begin{array}{l}-0.63 \\
(0.78)\end{array}$ & $0.91(0.95)$ & $-0.33(0.71)$ & $\begin{array}{l}0.47 \\
(0.73)\end{array}$ & $\begin{array}{l}-0.01 \\
(0.67)\end{array}$ \\
\hline \multirow[t]{2}{*}{$\begin{array}{l}\text { Other/ } \\
\text { unknown race }\end{array}$} & Clinton & 3.07 & $\begin{array}{l}-0.09 \\
(0.42)\end{array}$ & $0.59(0.52)$ & $\begin{array}{l}0.04 \\
(0.45)\end{array}$ & $0.91(0.60)$ & $0.05(0.50)$ & $\begin{array}{l}0.48 \\
(0.63)\end{array}$ & $0.48(0.58)$ \\
\hline & Trump & 5.73 & $\begin{array}{l}-1.43 \\
(0.78)\end{array}$ & $\begin{array}{l}-0.87 \\
(0.80)\end{array}$ & $\begin{array}{l}-1.00 \\
(0.86)\end{array}$ & $\begin{array}{l}-1.22 \\
(0.91)\end{array}$ & $\begin{array}{l}-1.56 \\
(0.77)^{*}\end{array}$ & $\begin{array}{l}-1.60 \\
(0.77)^{*}\end{array}$ & $\begin{array}{l}-0.95 \\
(0.79)\end{array}$ \\
\hline
\end{tabular}

Linear regression adjusted for age group, sex, racelethnicity, income, educational attainment, state, and 6 months of pre-November trends SE standard error. ${ }^{*} p<0.05, * * p<0.01, * * * p<0.001$

December and January that suggests that some groups may have benefited. In our subgroup analysis, only men in Trump states had a significant improvement in poor mental health days and ionly $\mathrm{n}$ January 2017 . Overall, there is insufficient evidence to suggest that Trump's election victory had a beneficial impact on mental health for Trump voters overall.

The rise in depression in Trump states beginning 3 months after the election suggests that there were likely other coinciding factors, especially as time elapsed further from election day, contributing to depression. In particular, the USA faced a concurrent epidemic of rising opioid deaths during this period that killed over 47,000 in 2017 and especially affected many states that voted for Trump including West Virginia, Ohio, and Pennsylvania. ${ }^{7,8}$ Furthermore, the USA has been experiencing a decade-long rise in depression nationally. ${ }^{7,9,10}$ In addition, the newly installed Trump administration enacted a myriad of executive orders in early 2017, the scope of which is beyond that of this study but important to consider in assessing mental health in the months following his inauguration.

This study has several limitations. This is a cross-sectional study based on a national survey taken monthly, not a longitudinal cohort study. Therefore, we could not monitor the mental health of respondents over time and, similarly to comparing election polls, depended on the study sample being representative of the population, an assumption made more likely with the use of BRFSS survey weights in our analysis. As a non-randomized study, this analysis cannot definitively establish a causal relationship from the election results to changes in mental health but instead offers evidence in support or against plausible causal pathways. Because the respondents' candidate preference and party affiliation are unknown, 

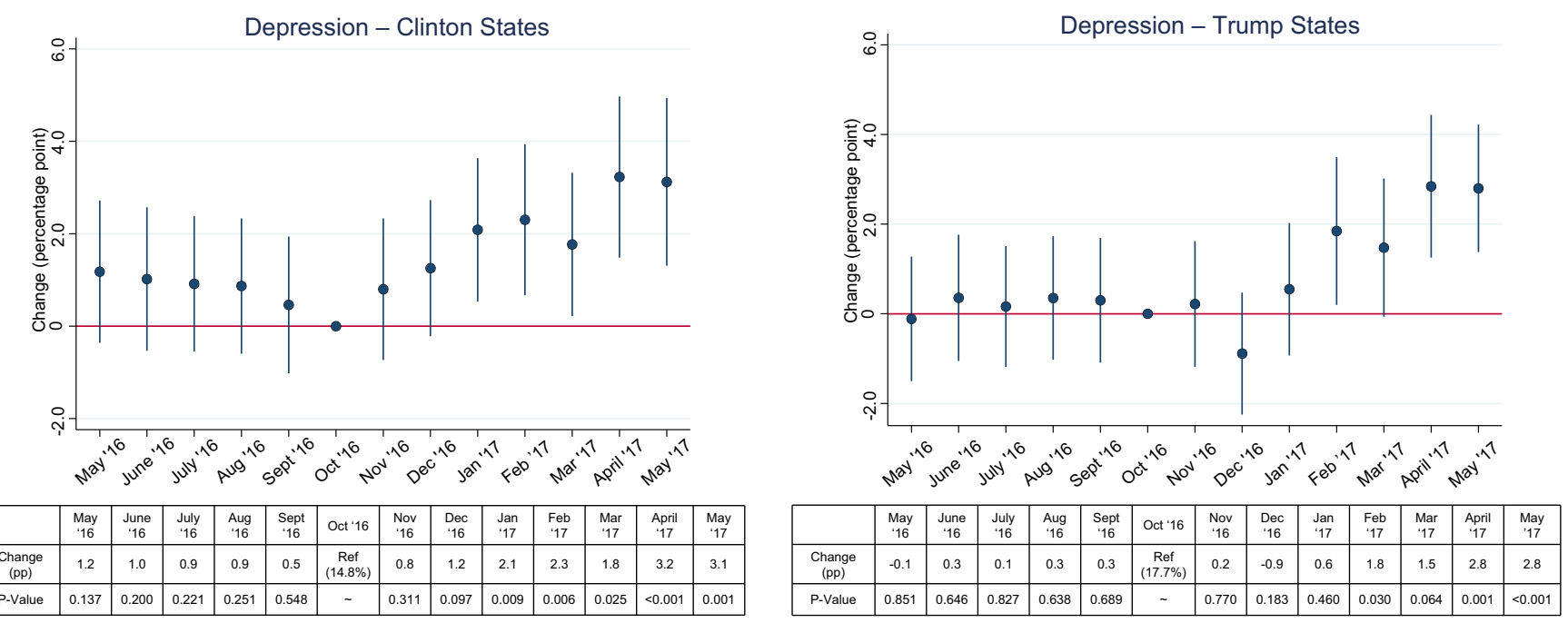

Figure 2 Adjusted changes in depression rates in each month compared to October 2016 stratified by states that voted for Clinton and states that voted for Trump.

we rely on the candidate's margin of victory or loss in a state as a proxy to assess which candidate's voters experienced changes in mental health. The BRFSS survey data are selfreported, which are not as reliable as clinical records. In particular, the depression measure relies on a respondent's memory of a health care professional diagnosing them and willingness to report. The depression question is also not an indicator of one's depression at time of interview but whether such a diagnosis has been given at any time in one's history. Therefore, we make the assumption that changes in this

Table 2 Changes in Depression Rate Between Each Month and October 2016 Stratified by Age, Sex, Race/Ethnicity, and State Group

\begin{tabular}{|c|c|c|c|c|c|c|c|c|c|}
\hline \multirow[b]{2}{*}{ Demographic } & \multirow[b]{2}{*}{$\begin{array}{l}\text { State } \\
\text { group }\end{array}$} & \multirow{2}{*}{$\begin{array}{l}\text { Unadjusted } \\
\text { depression } \\
\text { rate, October } \\
2016 \\
\text { (reference), \% }\end{array}$} & \multicolumn{7}{|c|}{ Adjusted percentage point change in rate versus October 2016 (SE) } \\
\hline & & & $\begin{array}{l}\text { November } \\
2016\end{array}$ & $\begin{array}{l}\text { December } \\
2016\end{array}$ & $\begin{array}{l}\text { January } \\
2017\end{array}$ & $\begin{array}{l}\text { February } \\
2017\end{array}$ & March 2017 & $\begin{array}{l}\text { April } \\
2017\end{array}$ & May 2017 \\
\hline \multicolumn{10}{|l|}{ Age group } \\
\hline \multirow[t]{2}{*}{ Age 18-34 } & Clinton & 14.7 & $0.8(1.6)$ & $2.2(1.7)$ & $3.9(1.8)^{*}$ & $2.6(1.8)$ & $2.1(1.8)$ & $4.4(1.9)^{*}$ & $4.6(2.1)^{*}$ \\
\hline & Trump & 17.9 & $-0.8(1.6)$ & $-2.5(1.5)$ & $0.6(1.6)$ & $1.4(1.6)$ & 1.0 (1.6) & $1.3(1.5)$ & $3.2(1.5) *$ \\
\hline \multirow[t]{2}{*}{ Age $35-54$} & Clinton & 16.3 & $-1.2(1.3)$ & $0.3(1.3)$ & $\begin{array}{l}-0.4 \\
(1.3)\end{array}$ & $1.6(1.4)$ & $0.8(1.4)$ & $2.3(1.6)$ & $-0.2(1.3)$ \\
\hline & Trump & 19.3 & $0.3(1.4)$ & $-0.6(1.4)$ & $0.4(1.4)$ & $0.9(1.6)$ & $2.2(1.5)$ & $3.7(1.7)^{*}$ & $2.8(1.4)^{*}$ \\
\hline \multirow{2}{*}{ Age $55-64$} & Clinton & 17.3 & $1.6(1.7)$ & $2.2(1.9)$ & $2.5(1.7)$ & $0.8(1.7)$ & $1.4(1.7)$ & $3.2(2.1)$ & $5.7(2.6)^{*}$ \\
\hline & Trump & 19.9 & $2.4(1.5)$ & $0.4(1.4)$ & $0.9(1.7)$ & $3.9(2.1)$ & $0.8(1.7)$ & $3.5(1.6)^{*}$ & 2.7 (1.6) \\
\hline \multirow[t]{2}{*}{ Age $65+$} & Clinton & 11.1 & $3.2(1.6)$ & $0.9(1.1)$ & $3.2(1.3)^{*}$ & $4.0(1.6)^{*}$ & $3.4(1.2)^{* *}$ & $3.0(1.5)^{*}$ & 4.0 \\
\hline & Trump & 13.4 & $-0.2(1.1)$ & $-0.5(1.0)$ & $0.6(1.2)$ & $1.5(1.5)$ & $1.3(1.3)$ & $\begin{array}{l}3.7 \\
(1.3)^{* *}\end{array}$ & $2.2(1.1)^{*}$ \\
\hline \multicolumn{10}{|l|}{ Sex } \\
\hline \multirow[t]{2}{*}{ Male } & Clinton & 10.6 & $-0.8(1.6)$ & $-2.5(1.5)$ & $0.6(1.6)$ & $1.4(1.6)$ & $1.0(1.6)$ & $1.3(1.5)$ & $3.2(1.5)^{*}$ \\
\hline & Trump & 13.2 & $2.4(1.5)$ & $0.4(1.4)$ & $0.9(1.7)$ & $3.9(2.1)$ & $0.8(1.7)$ & $3.5(1.6) *$ & $2.7(1.6)$ \\
\hline \multirow[t]{2}{*}{ Female } & Clinton & 18.8 & $0.3(1.4)$ & $-0.6(1.4)$ & $0.4(1.4)$ & 0.9 (1.6) & $2.2(1.5)$ & $3.7(1.7)^{*}$ & $2.8(1.4)^{*}$ \\
\hline & Trump & 21.9 & $-0.2(1.1)$ & $-0.5(1.0)$ & $0.6(1.2)$ & $1.5(1.5)$ & $1.3(1.3)$ & $\begin{array}{l}3.7 \\
(1.3)^{* *}\end{array}$ & $2.2(1.1)^{*}$ \\
\hline \multicolumn{10}{|l|}{ Race/ethnicity } \\
\hline \multirow[t]{2}{*}{ White } & Clinton & 17.7 & $-0.2(0.9)$ & $1.2(1.0)$ & $1.9(1.0)$ & $1.5(1.0)$ & $1.6(1.0)$ & 2.8 & $2.6(1.0)^{*}$ \\
\hline & Trump & 18.8 & $0.1(0.8)$ & $-0.8(0.8)$ & $0.9(0.9)$ & $1.9(0.9)^{*}$ & $1.6(0.9)$ & $\begin{array}{l}2.4 \\
(0.8) * *\end{array}$ & $\begin{array}{l}3.5 \\
(0.8) * * *\end{array}$ \\
\hline \multirow[t]{2}{*}{ Black } & Clinton & 12.8 & $0.7(2.5)$ & $1.5(2.4)$ & $2.4(2.6)$ & $1.5(2.6)$ & $2.2(2.6)$ & $3.5(3.2)$ & $0.1(2.7)$ \\
\hline & Trump & 15.4 & $3.0(2.2)$ & $-0.8(2.1)$ & $0.1(2.2)$ & $0.0(2.3)$ & $0.4(2.1)$ & $6.8(2.9)^{*}$ & $1.9(2.1)$ \\
\hline \multirow{2}{*}{ Hispanic } & Clinton & 11.0 & $2.9(2.0)$ & $2.9(1.8)$ & $2.0(1.9)$ & $1.8(2.2)$ & $1.6(2.2)$ & $3.8(2.2)$ & $4.4(2.6)$ \\
\hline & Trump & 13.8 & $-2.0(2.6)$ & $-4.3(2.4)$ & $\begin{array}{l}-1.3 \\
(2.5)\end{array}$ & $2.0(3.2)$ & $1.6(2.9)$ & $2.2(2.8)$ & $0.2(2.5)$ \\
\hline Other/ & Clinton & 8.9 & $2.4(2.6)$ & $0.0(1.9)$ & $2.2(2.0)$ & $6.2(2.8)^{*}$ & $2.2(1.9)$ & $4.4(2.6)$ & $5.2(2.9)$ \\
\hline unknown race & Trump & 17.1 & $-0.2(2.7)$ & $1.9(2.9)$ & $0.3(2.9)$ & $4.2(4.1)$ & $1.9(2.8)$ & $-0.1(2.8)$ & $1.0(2.7)$ \\
\hline
\end{tabular}

Linear regression adjusted for age group, sex, racelethnicity, income, educational attainment, state, and 6 months of pre-November trends $S E$ standard error. $* p<0.05, * * p<0.01, * * * p<0.001$ 


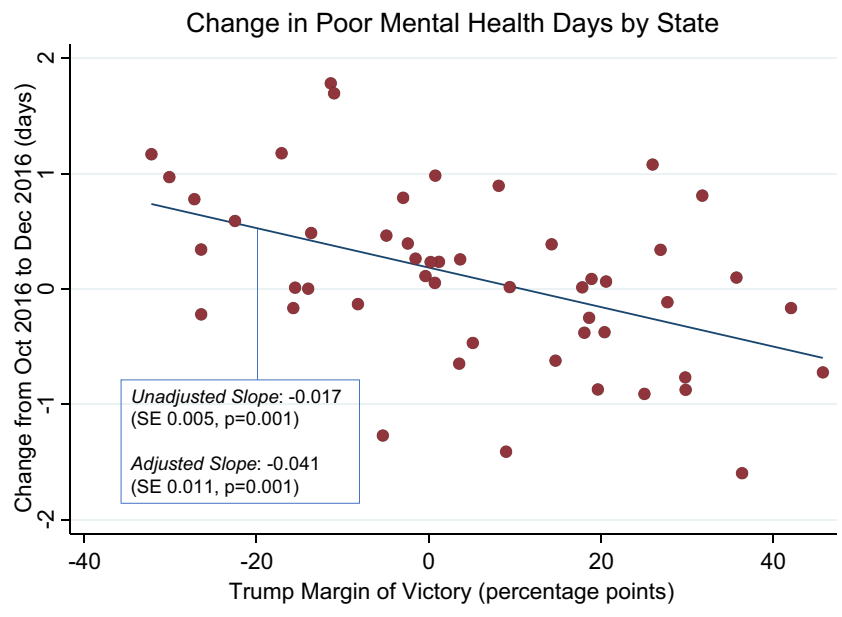

Figure 3 Change in poor mental health days from October 2016 to December 2016 by Trump's margin of victory of loss in each state. Note:District of Columbia was an outlier value at a-86-percentage point margin of victory and therefore excluded from this analysis.

measure over time (i.e., before and after the 2016 election) are largely attributable to newly diagnosed cases. Finally, there may be differences in access to care for adults living in states that voted for Clinton compared with states that voted for Trump, which may not be accounted for in this study.

Overall, with nearly 55 million more days of poor mental health among the 109.2 million adults living in Clinton states in December than October 2016 alone, primary care providers, mental health professionals, and the public should not overlook the potential effects from the 2020 election. The usual approaches to depression screening and mental health care may be insufficient, especially with falling primary care visits in the COVID-19 era. ${ }^{11}$ The situation is worsened by increased social isolation, substance use, and mental health distress as well as missed or delayed diagnoses during the pandemic. ${ }^{11-13}$ A review of mental health interventions during pandemics concluded that involving patients in their care over a sustained period of time, digital and social media outreach, and resilience-building sessions are potentially promising interventions in a pandemic setting. ${ }^{14}$ In addition to regular primary care screening for depression and subsequent treatment and follow-up as recommended by U.S. Preventives Services Task Force 2016 guidelines, providers could specifically inquire about election-related stress and distress when clinically appropriate. ${ }^{15}$ Our study suggests that older adults and voters of the losing candidate may be most at risk for mental health deterioration.

\section{CONCLUSIONS}

Our study reveals a concerning rise in poor mental health and depression in states that voted for the losing presidential candidate shortly following the 2016 election that was not observed in states that voted for the winning candidate. Health care providers could potentially help patients in the 2020 election by monitoring for clinically relevant signs of mental health deterioration and offering appropriate support and intervention. In the long term, more research into the impact of elections on mental health is needed to facilitate a more datadriven and holistic approach to care for patients experiencing election-related stress.

Corresponding Author: Brandon W. Yan, BA; Philip R. Lee Institute for Health Policy Studies and School of Medicine, University of California, San Francisco, 513 Parnassus Ave, Suite S-245, San Francisco, CA 94143, United States (e-mail: Brandon.Yan@ucsf.edu).

\section{Compliance with Ethical Standards:}

Conflict of Interest: The authors declare that they do not have a conflict of interest.

\section{REFERENCES}

1. Williams DR, Medlock MM. Health Effects of Dramatic Societal Events - Ramifications of the Recent Presidential Election. Malina D, ed. $N$ Engl $J$ Med. 2017;376(23):2295-2299. https://doi.org/10.1056/ NEJMms 1702111

2. Stress in America: Coping with Change. American Psychological Association; 2017:13. Accessed July 3, 2020. https://www.apa.org/news/ press/releases/stress/2016/coping-with-change.pdf

3. Krupenkin M, Rothschild D, Hill S, Yom-Tov E. President Trump Stress Disorder: Partisanship, Ethnicity, and Expressive Reporting of Mental Distress After the 2016 Election. SAGE Open. 2019;9(1):2158244019830865. https://doi.org/10.1177/ 2158244019830865

4. Majumder MS, Nguyen CM, Sacco L, Mahan K, Brownstein JS. Risk Factors Associated with Election-Related Stress and Anxiety before and after the 2016 US Presidential Election. PsyArXiv; 2017. https://doi.org/ 10.31234/osf.io/u4hns

5. Roche MJ, Jacobson NC. Elections Have Consequences for Student Mental Health: An Accidental Daily Diary Study: Psychol Rep. Published online April 5, 2018. https://doi.org/10.1177/0033294118767365

6. Summary Health Statistics: National Health Interview Survey, 2018. Accessed October 8, 2020. https://ftp.cdc.gov/pub/Health_Statistics/ NCHS/NHIS/SHS/2018_SHS_Table_A-18.pdf

7. Abuse NI on D. Opioid Overdose Crisis. National Institute on Drug Abuse. Published May 27, 2020. Accessed October 1, 2020. https://www. drugabuse.gov/drug-topics/opioids/opioid-overdose-crisis

8. Yan BW, Sloan FA, Boscardin WJ, Guo F, Dudley RA. The Opioid Epidemic Blunted the Mortality Benefit of Medicaid Expansion. Med Care Res Rev. Published online May 13, 2020. https://doi.org/10.1177/ 1077558720919620

9. Yu B, Zhang $\mathbf{X}$, Wang $\mathbf{C}$, Sun $\mathbf{M}$, Jin $\mathbf{L}$, Liu $\mathbf{X}$. Trends in depression among Adults in the United States, NHANES 2005-2016. J Affect Disord. 2020;263:609-620. https://doi.org/10.1016/j.jad.2019.11.036

10. 2017 Drug Overdose Death Rates. Centers for Disease Control and Prevention. Published March 18, 2020. Accessed October 1, 2020. https://www.cdc.gov/drugoverdose/data/statedeaths/drug-overdosedeath-2017.html

11. Mehrota A, Chernew M, Linetsky D, Hatch H, Cutler D. The Impact of the COVID-19 Pandemic on Outpatient Visits: Practices Are Adapting to the New Normal. The Commonwealth Fund; 2020. https://doi.org/10. 26099/ds9e-jm36

12. Czeisler MÉ, Lane RI, Wiley JF, et al. Mental Health, Substance Use, and Suicidal Ideation During the COVID-19 Pandemic - United States, June 24-30, 2020. MMWR Morb Mortal Wkly Rep. August 14, 20202020;69(32):1049-1057. https://doi.org/10.15585/mmwr. mm6932al 
13. Williams R, Jenkins DA, Ashcroft DM, et al. Diagnosis of physical and mental health conditions in primary care during the COVID-19 pandemic: a retrospective cohort study. Lancet Public Health. 2020;5(10):e543-e550. https://doi.org/10.1016/S2468-2667(20) 30201-2

14. Soklaridis S, Lin E, Lalani Y, Rodak T, Sockalingam S. Mental health interventions and supports during COVID- 19 and other medical pandemics: A rapid systematic review of the evidence. Gen Hosp Psychiatry. 2020;66:133-146. https://doi.org/10.1016/j.genhosppsych. 2020.08.007
15. Siu AL, Bibbins-Domingo $\mathbf{K}$, Grossman DC, et al. Screening for Depression in Adults: US Preventive Services Task Force Recommendation Statement. JAMA. 2016;315(4):380. doi:10.1001/jama.2015.18392

Publisher's Note Springer Nature remains neutral with regard to jurisdictional claims in published maps and institutional affiliations. 